E3S Web of Conferences 1, 06002 (2013)

DOI: $10.1051 / \mathrm{e} 3 \operatorname{sconf} / 20130106002$

(C) Owned by the authors, published by EDP Sciences, 2013

\title{
Mercury concentration in the sediments as a function of changing climate in coastal zone of Southern Baltic Sea - preliminary results
}

\author{
M. Bełdowska ${ }^{1}$, A. Jędruch ${ }^{2}$, J. Bełdowski $^{3}$ and M. Szubska ${ }^{4}$ \\ ${ }^{1}$ Institute of Oceanography, University of Gdansk, al. Pilsudskiego 46, 81-378 Gdynia, POLAND, \\ m.beldowska@ug.edu.pl \\ 2 Institute of Oceanography, University of Gdansk, al. Pilsudskiego 46, 81-378 Gdynia, POLAND, oceaje@gmail.com \\ ${ }^{3}$ Institute of Oceanology, Polish Academy of Sciences, ul. Powstancow Warszawy 55, 81-712 Sopot, POLAND, \\ hyron@iopan.gda.pl \\ ${ }^{4}$ Institute of Oceanology, Polish Academy of Sciences, ul. Powstancow Warszawy 55, 81-712 Sopot, POLAND, \\ szubi@iopan.gda.pl
}

\begin{abstract}
Mercury, despite of its many uses in industry, is also highly toxic. It is highly neurotoxic, and because of the ability of mercury to penetrate placental barrier, in some countries ban on predatory fish consumption (the main route of mercury into human organism) by pregnant women was introduced. There are very little publications describing the consequences of weather anomalies on contaminants cycles. No research was published concerning the reemission of $\mathrm{Hg}$ due to climate change in the Southern Baltic Sea. The study area was situated in the coastal zone of the Gulf of Gdansk - the Southern Baltic. Samples of different species of macrophytobenthos were collected once a month during 2006-2012. Samples of Potamogeton pectinatus, sediments and pore waters were collected once a month from February 2011 to January 2012. The climate changes in the moderate latitudes: extension of the fall season, has contributed to stabilization of high concentrations of mercury in pore waters. Lack of ice cover in the coastal zone and simultaneous occurrence of storms had an impact on supply of the organic matter to the sediments and the increased concentration of $\mathrm{Hg}$. More intense burning of fossil fuels in this season favored the increased metal concentration in the atmosphere and consequently an increase of the atmospheric deposition of metals to the sediments. This led to a fourfold increase of the mercury concentration in sediments as compared to fall season.
\end{abstract}

Key words: mercury, porewater, sediments, climate change, coastal zone, aquatic vascular plants

\section{Introduction}

Despite its undoubtful usefulness, mercury is characterized with high toxicity. Mercury is the most toxic metal and one of the most toxic elements. So far, no positive functions of mercury in organisms are known. It is highly neurotoxic, causing autism in children, while in adults it is responsible for Alzheimer, and Parkinson diseases as well as schizophrenia and depression (Zahir et al. 2005; Bose-O'Reilly et al. 2010). Mercury was used for ages by man. In the 20th century its usage increased rapidly in many branches of industry. Since 1950's, when several hundred of people died after consumption of polluted fish, scientists has started to realize how toxic mercury is (Ebinghaus et al. 1999). That kind of disasters, contributed to introduce restricted regulation of mercury usage, and hence affected reduced emissions to the environment. According to the HELCOM report, mercury input to the Baltic Sea has decreased by $44 \%$ since 1990's (Korpinen et al. 2010).

Climate changes in the Southern Baltic Sea region head towards shortening of icing period (KLIMAT, 2011). As a consequence, fluxes of chemical substances in the surface sediments of the coastal zone are affected. The period, in which mercury is reemitted from sediments into nearbottom water and food chain lengthens During fall and winter, intensive inflow of $\mathrm{Hg}$ from atmosphere and due to storms from land outflow and erosion is observed. It was calculated, that currently due to diffusion and resuspension about $50 \%$ of mercury deposited onto the floor of the Gdansk Basin is reemitted from marine sediments back to water column. If the input of mercury to sediments increases, the reemission will increase from several to several dozen percents more than 
the increase of the input (Bełdowski et al. 2009). In this way marine sediments might become significant diffuse mercury source, which cannot be controlled by any reasonable means.

The main aim of the project founded by National Science Centre (NSC UMO-2011/01/ B/ST10/07697) was to assess the influence of prolonged warm season on the sediment-water exchange of mercury in the Gdansk Basin as well as the determination of direction and rate of sediment/water mercury flux in terms of shorter icing period of the Baltic Sea.

\section{Materials and Methods}

The study area was situated in the coastal zone of the Gulf of Gdansk - the Southern Baltic. Samples of different species of macrophytobenthos were collected once a month during 2006-2010 at the station located near Hel, Jastarnia, Swarzewo, Oslonino, Rewa, Mechelinki, Gdynia, Sopot, Gdansk, Mikoszewo and Krynica Morska. Samples of Potamogeton pectinatus, sediments and pore waters were collected once a month from February 2011 to January 2012 at Oslonino station. This station was located in a small bay with restricted water exchange. Small depth and the structure of the bay were enhancing intensive growth of aquatic organisms, leading, together with low water dynamics, to the accumulation of organic matter. It had a direct influence on the physical and chemical conditions (light, dissolved oxygen) prevailing at this station.

Water samples for mercury analysis were oxidised by the addition of $\mathrm{BrCl}$ and pre-reduced with hydroxylamine hydrochloride solution 1 hour prior to analysis by CV-AFS (TEKRAN 2600), according to US EPA method 1631 (US EPA, 2002). Quality control procedures for water samples included blanks and water spiked with mercury nitrate in the range of $0.5-25 \mathrm{ng} \cdot \mathrm{L}^{-1}$, and produced adequate precision ( $1 \% \mathrm{RSD})$ and recovery $(98-99 \%)$. The samples of the biological and sediment material were analyzed by means of CV-AAS (AMA 254). Detection limit for solid materials was $0.005 \mathrm{ng} \cdot \mathrm{g}^{-1}$; while for water it was as low as $0.05 \mathrm{ng} \cdot \mathrm{L}^{-1}$.

\section{Results and Discussion}

During 2006-2010, in majority of analyzed macrophytobentos in the Polish coastal zone of Baltic Sea, the average concentration of mercury was several times lower than measured by Boszke et al. (2003) in the same area in 1995-1998, which indicates the improvement of water quality (Fig. 1).

Considering the average concentration of mercury in the aquatic vascular plants (Potamogeton pectinatus, Ruppia maritima) from the Gulf of Gdansk, it was maintained at a similar level as in previous years. These plants adsorbed metals mainly from sediments, where concentration of mercury has not changed in the short time scale. Release of mercury accumulated in sediments to the pore waters affects adsorption of this metal by aquatic vascular plants. In the years 2006-2012 mercury concentrations in this group of phytobenthos were higher than in analyzed green algae (Chlorophyta and Charophyta), what confirms reemission of $\mathrm{Hg}$ from the sediments. This is the opposite trend than the one observed in the years 1995-1998. Prolonged warm season and shorter icing period in the Southern Baltic coastal zone, causes the elongation of the release of toxic substances from sediments into the trophic chain. Despite of the limitation of anthropogenic mercury loads, the climate changes in the moderate latitudes caused that the amount of this metal getting to the marine organisms not decreasing proportionally .

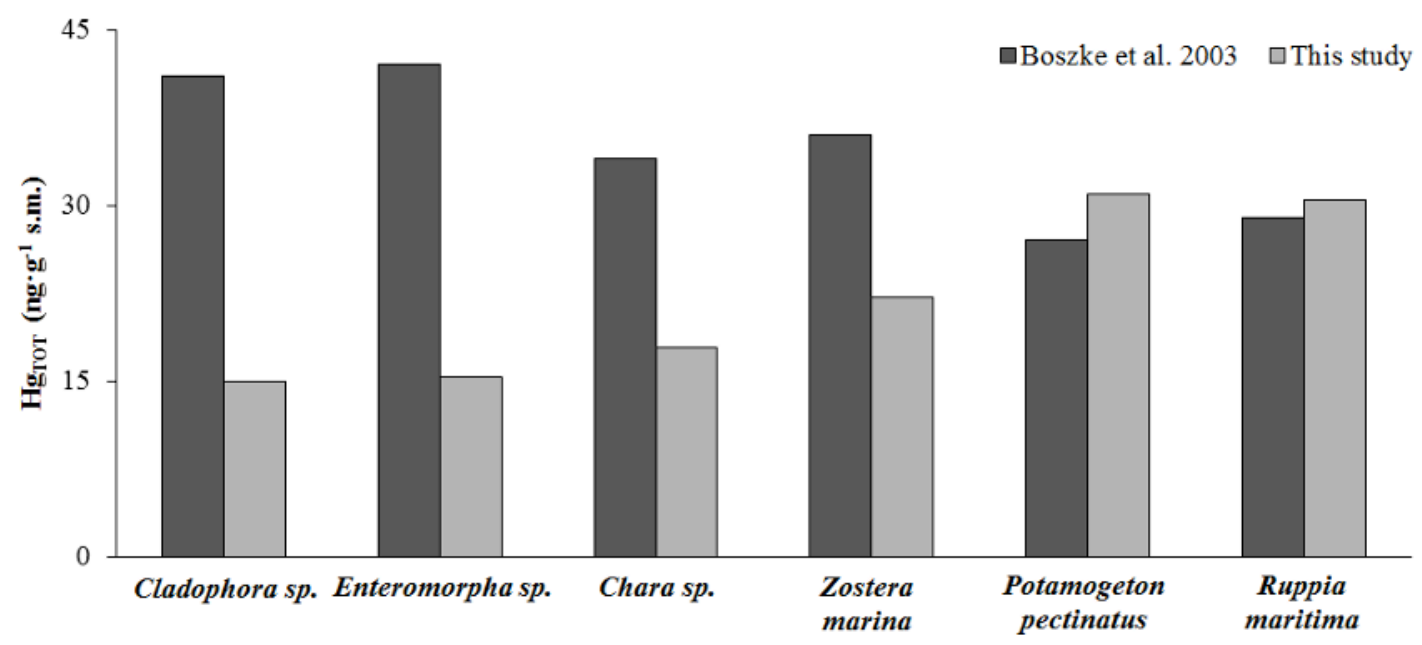

Figure 1. Hg concentration (ng $\cdot \mathrm{g}^{-1}$ d.w.) in macrophytobenthos from the coastal stations of the Southern Baltic Sea in years 1995-1998 (Boszke et al. 2003) and 2006-2010

In February 2011 the ice pack was present only partially in Gulf of Gdansk while in March the gulf was completely iced over in this area (winter I). In result the suspension of organic matter and $\mathrm{Hg}$ into sediments was restricted. In this time concentration of $\mathrm{Hg}$ in porewater was an order of magnitude smaller than in other seasons (Fig. 2). High concentration of $\mathrm{Hg}$ in Potamogeton pectinatus was caused by the transport of this metal from porewater into phytobenthos which growth was hardly inhibited. (Fig. 3). 
a)

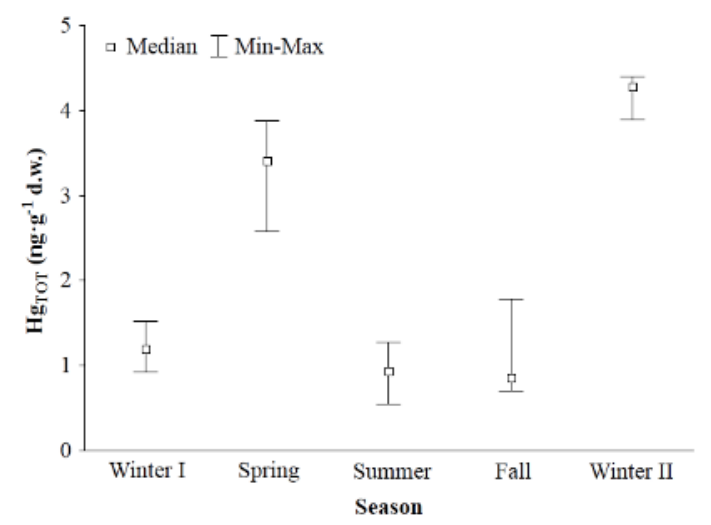

b)

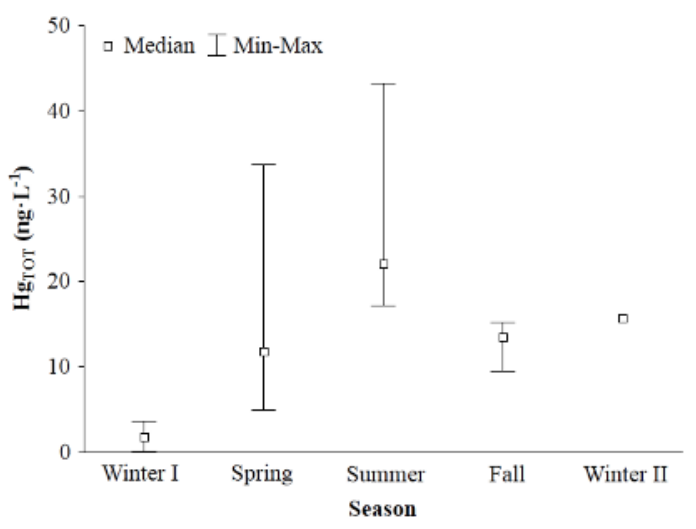

Figure 2. $\mathrm{Hg}$ concentration in a) sediments $\left(\mathrm{ng} \cdot \mathrm{g}^{-1} \mathrm{~d}\right.$.w. $)$; b) porewater $\left(\mathrm{ng} \cdot \mathrm{L}^{-1}\right)$ at Oslonino coastal station of the Southern Baltic Sea

During spring season rapid increase of $\mathrm{Hg}$ in sediment was observed, due to the influx of metals and organic matter, inter alia from melting ice and snow. In consequence concentration of $\mathrm{Hg}$ in pore water raised along. Higher solar radiation favored growth of phytobenthos which in turn led to the decrease of metal concentration (Fig. 2, Fig. 3).

Further increase of solar radiation and water temperature favored reemission of $\mathrm{Hg}$ accu-mulated in sediment into porewaters (Fig 2). In consequence concentration of metal in the sediment was the smallest, while concentrations in porewaters and in Potamogeton pectinatus were the greatest of all studied cases. High concentration of metal in aboveground parts of phytobenthos was caused by both the transport from roots and more intensive accumulation from water during warm season (Fig. 3). This is confirmed by a significant correlation of $\mathrm{Hg}$ concentration in leaves and roots $(\mathrm{r}=$ $0.86)$ and $\mathrm{Hg}$ concentration in leaves and stem $(\mathrm{r}=0.93)$.

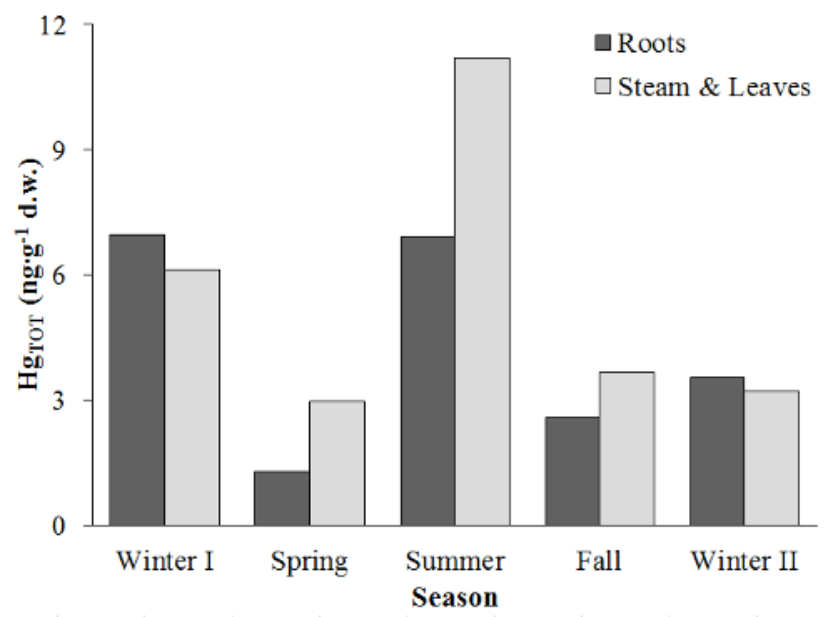

Figure 3. $\mathrm{Hg}$ concentration in different parts of Potamogeton pectinatus from coastal station of the Southern Baltic Sea

Starting from July, with decreasing solar radiation, reemission of $\mathrm{Hg}$ from sediment to pore water was limited. In consequence concentration $\mathrm{Hg}$ in porewater at fall was similar to that from spring (Fig. 2). In December when air temperatures were abnormally high for this season, concentration of $\mathrm{Hg}$ in the porewater increased with simultaneous decreased of mercury concentration in the sediment.

Recorded climate changes in the Southern Baltic Sea region indicate the shortening of cold season. First half of January was warm (air temperature on average $4.5^{\circ} \mathrm{C}$ ) with lack of ice cover, and due to an increase of organic matter amount from land (storms) and input of atmospheric deposition mercury. In consequence concentration of $\mathrm{Hg}$ in sediment during winter II was four times higher than during winter I. While values for porewater concentration showed tenfold increase between the two winters (Fig. 2).

\section{Conclusion}

Extension of the fall season has contributed to stabilization of high concentrations of mercury in pore waters. Lack of ice cover in the coastal zone and simultaneous occurrence of storms had an impact on supply of the organic matter to the sediments and the increased concentration of $\mathrm{Hg}$ (in sediments). More intense burning of fossil fuels in this season favored the increased metal concentration in the atmosphere and consequently an increase of the atmospheric deposition of metals to the sediments. This led to a fourfold increase of the mercury concentration in sediments as compared to fall season.

Pilot studies (2006-2008 years) in the Gulf of Gdansk had shown, that mercury concentrations in marine vascular plants were significantly higher during cold winter with complete ice cover than in other seasons (Saniewska et al. 2010). During the warm, mild winter which took place in January 2012, there was no such increase - the concentration of $\mathrm{Hg}$ in aquatic vascular plants was similar to values measures in the fall.

Climate changes influence the cycle of toxic mercury. Trends of that changes should be recognized. Within the project funded by National Science Centre (nr 
NSC UMO-2011/01/B/ ST10/07697) 2012-2014 an attempt to estimate inter alia; The influence of prolonged warm season on the sediment-water exchange of mercury in the Gdansk Basin; The influence of snow cover and Baltic icing on the mercury input into the sea and fluxes at the sediment/water interface; The influence of strong winds/gales and the increase of mean wave height on the remobilization of terrestrial and coastal sediments bound mercury; Assessment of the climate change influence on the remobilization of historical mercury deposits into the Gulf of Gdansk.

\section{Acknowledgements}

The authors thank the financial supports provided from National Science Centre (nr NSC UMO2011/01/B/ST10/07697) 2012-2014.

\section{References}

Bełdowski J, Miotk M, Pempkowiak J. Mercury fluxes through the sediment water interface and bioavailability of mercury in Southern Baltic Sea sediments, Oceanologia 2009; 51: 263-285.

Bose-O'Reilly S, McCarty KM, Steckling N, Lettermeier B. Mercury exposure and children health. Curr Probl Pediatr Adolesc Health Care 2010;40:186-215.

Boszke L, Siepak J, Falandysz F. Total mercury contamination of selected organisms in Bay of Puck, Baltic Sea, Poland. Pol J Environ Stud 2003;12:275285.

Ebinghaus R, Turner RR, Lacerda LD, Vasiliev O, Salomons W. Mercury contaminated sites. Berlin: Springer; 1999.538 p.
KLIMAT. project „Influence of climate changes on environment, economy, society", nr. POIG.01.03.01-14-011/08 - 00, Project founded by European Union, 2011,www.klimat.imgw.pl

Korpinen S, Laamanen M, Andersen JH, Asplund L, Berger U, Bignert A, Boalt E, Broeg K, Brzozowska A, CatoI, Durkin M, Garnaga G, Gustavson K, Haarich M, Hedlund B, Köngäs P, Lang T, Larsen MM, Lehtonen K, Mannio J, Mehtonen J, Murray C, Nielsen S, Nyström B, Pazdro K, Ringeltaube P, Schiedek D, Schneider R, Stankiewicz M, Strand J, Sundelin B, Söderström M, Vallius H, Vanninen P, Verta M, Vieno N, Vuorinen PJ, Zahharov A. Hazardous substances in the Baltic Sea - An integrated thematic assessment of hazardous substances in the Baltic Sea. Balt. Sea Environ. Proc. No. 120B; Helsinki Commission, Finland 2010. 119 p.

Saniewska D, Bełdowska M, Bełdowski J, Saniewski M, Kwaśniak J, Falkowska L. Distribution of mercury in different environmental compartments in the aquatic ecosystem of the coastal zone of Southern Baltic Sea. J Environ Sci 2010;22:1144-1150.

US EPA. Method 1631, Revision E: Mercury in water by oxidation, purge and trap, and cold vapor atomic fluorescence spectrometry. US Environmental Protection Agency, Office of Water 4303, EPA-821R-02-019; 2002. 38 p.

Zahir F, Rizwi SJ, Haq SK, Khan RH. Low dose mercury toxicity and human health. Environ Toxixol Pharmacol 2005;20:351-360. 